\title{
Rancang Bangun Alat dan Aplikasi untuk para Penyandang Tunanetra Berbasis Smartphone Android
}

\author{
Dendy Pratama $^{1 *}$, Denisson Arif Hakim ${ }^{1}$, Yuhif Prasetya ${ }^{1}$, Nur Rizki Febriandika ${ }^{1}$, Marleny Trijati ${ }^{1}$, \\ Umi Fadlilah ${ }^{2}$ \\ Jurusan Teknik Elektro \\ Universitas Muhammadiyah Surakarta \\ Surakarta \\ *dendyp760@gmail.com \\ ${ }^{2}$ Program Studi Informatika \\ Universitas Muhammadiyah Surakarta \\ Surakarta \\ umi.fadlilah@ums.ac.id
}

\begin{abstract}
ABSTRAK
Kemajuan ilmu pengetahuan dan teknologi berperan mewujudkan kehidupan masyarakat yang lebih baik. Salah satunya adalah kemajuan teknologi elektronika yang telah melekat di dalam kehidupan manusia. Berbagai alat elektronika praktis dan fleksibel telah banyak diciptakan sehingga membantu memudahkan manusia dalam memenuhi kebutuhannya. Oleh sebab itu penulis ingin membuat novel audio untuk penyandang tunanetra yang disajikan dalam bentuk audio yang sudah diedit seperti menonton film yang dibuat dari hasil rekaman. Alat yang penulis buat berbasis android yang dipadukan dengan modul bluetooth dan arduino berfungsi memanggil hasil rekaman yang sudah diedit untuk memudahkan penyandang tunanetra serta headset dan speaker sebagai keluaran dari android. Dengan alat yang penulis ciptakan diharapkan para penyandang tunanetra menjadi bisa menikmati novel tanpa harus menggunakan huruf brailler yang ada pada novel saat ini hanya sedikit jumlahnya.
\end{abstract}

Kata Kunci : Android, Novel AudioVisual

\section{Pendahuluan}

Para penyandang tunanetra sangat rentan terhadap stres dan depresi. Keterbatasan fisik membuat mereka terkendala dalam mengakses informasi, hiburan maupun hal-hal lainnya yang mampu diperoleh orang normal. Oleh sebab itu kebanyakan penderita tunanetra kurang memperoleh asupan motivasi, hiburan dan nasihat.

Salah satu hal yang tidak dapat diakses atau dilakukan para penyandang tunanetra adalah membaca novel. Padahal novel sendiri sarat akan hiburan, motivasi maupun nasihat. Banyak manfaat yang dapat diambil dari membaca novel, seperti melatih otak, menghilangkan stres, meningatkan konsentrasi dan imajinasi serta mampu memberikan dunia baru bagi pembaca.

Membaca novel tidaklah sama dengan menonton sebuah film di televisi. Membaca novel dapat merangsang daya imajinasi para pembaca dari tiap-tiap kata yang tertuliskan. Lebih jauh lagi, dengan membaca novel seseorang dapat seolah-olah masuk dalam situasi dari cerita tersebut. Oleh sebab itu sangat tepat menjadikan novel sebagai media atau alat yang digunakan untuk memberikan motivasi dan semangat bagi pembacanya.

Berdasarkan permasalahan tersebut, kami bermaksud untuk membuat sebuah novel motivasi dalam bentuk audio agar bisa diakses oleh penyandang tunanetra. Alur cerita akan dibuat sebaik mungkin sehingga mampu membuat para penyandang tunanetra terinspirasi. Tokohtokoh yang ada dalam kisah tersebut juga mengisahkan tentang perjalanan seorang penyandang tunanetra. Hal tersebut diharapkan agar sebuah cerita memiliki unsur kedekatan dengan para pembaca yang segmentasinya adalah penyandang tunanetra.

Audio-novel ini merupakan sebuah alat menyerupai box yang di dalamnya berisi sebuah novel, tentu saja dalam bentuk audio. Hal ini dapat menjadi semacam gebrakan baru di industri penerbitan bahwa novel tidak hanya bisa dinikmati dengan dibaca saja namun juga dapat melalui suara. Terlebih lagi temuan fakta bahwa di Indonesia masih banyak penyandang tunanetra sehingga membuat pembuatan audio novel ini menjadi penting demi memenuhi kebutuhan mereka terhadap hiburan dan motivasi. Sudah saatnya para penderita disabilitas mendapatkan perhatian yang selayaknya.

\section{Metode}

\subsection{Telaah Penelitian}

penelitian yang sudah ada mengenai sistem pengubah teks ke suara pada aplikasi penerjemahan Bahasa Indonesia 
dan Inggris secara real time berbasis smartphone android yang diteliti oleh Muh. Rizki Dwiyanto. Secara garis besar penelitian ini bertujuan mengubah test menjadi suara lalu diterjemahkan ke dalam Bahasa Indonesia atau Bahasa Inggris yang menggunakan smarthphone berbasis sistem operasi android menggunakan pemrograman aplikasi java yang berbasis android.

Untuk mengubah teks menjadi suara menggunakan aplikasi eclipse juno yang sudah dilengkapi dengan SDK Android dan Android Development Tools (ADK). Dengan aplikasi Penerjemahan Bahasa indonesia dan Inggris telah beroperasi sesuai dengan perancangan yang dibuat. Selain itu, fitur voice input-output yang digunakan pada aplikasi dapat digunakan baik oleh aplikasi. serta ukuran tampilan aplikasi dapat menyesuaikan ukuran layar smartphone.

Penelitian selanjutnya tentang Pengontrolan Lampu dengan menggunakan Suara Easy VR alat ini memudahkan kita menyalakan lampu tanpa harus berjalan ketitik saklar untuk menekannya tetapi hanya cukup berbicara dan menyebutkan kode-kode yang akan kita kontrol. Alat ini dengan menggunakan Easy VR yang dihubungkan dengan mikrokontroler arduino untuk mengkontrol alat - alat elektronik yang akan kita kendalikan. Prinsip kerja alat ini adalah dengan menggunakan Modul EasyVR, Mikrokontroler ATMega328 dan Relay setelah itu jika frekuensi suara cocok maka akan lampu akan nyala atau mati sesuai dengan apa yang disebutkan.

\subsection{Landasan Teori.}

1) Arduino.

Arduino adalah kit elektronik atau papan rangkaian elektronik open source yang di dalamnya terdapat komponen utama sebuah chip mikrokontroler dengan jenis AVR (Automatic Voltage Regulator) dari perusahaan Atmel. Gambar 1 memperlihatkan bentuk fisik Arduino Uno R3.

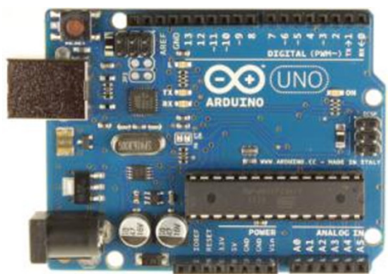

Gambar 1 Bentuk fisik Arduino Uno R3

Mikrokontroler tersebut berupa chip atau IC (integrated circuit) yang bisa diprogram menggunakan komputer. Tujuan menanamkan program pada mikrokontroler adalah agar rangkaian elektronik dapat membaca masukan, memproses masukan tersebut dan kemudian menghasilkan keluaran sesuai yang diinginkan. Jadi mikrokontrole bertugas sebagai 'otak' yang mengendalikan masukan, proses dan keluaran sebuah rangkaian elektronik. komponen utama Arduino adalah mikrokontroler, maka Arduino pun dapat diprogram menggunakan komputer sesuai kebutuhan.

\section{2) Android}

Android Merupakan sebuah sistem operasi yang berbasis Linux untuk telepon seluler seperti telepon pintar dan komputer tablet. Android menyediakan platform terbuka bagi para pengembang untuk menciptakan aplikasi mereka sendiri untuk digunakan oleh bermacam peranti bergerak.

Android pada alat yang kami gunakan berfungsi sebagai perekam serta tempat menyimpan hasil rekaman dan android ini juga memudahkan kami dalam hal memprogram yang disambungkan dengan WP3A.

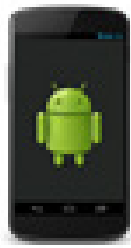

Gambar 2 Bentuk nyata Android)

\section{3) Modul Bluetooth}

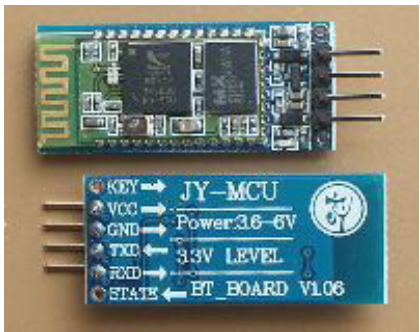

Gambar 3. Bentuk fisik modul Bluetooth

Bluetooth adalah salah satu bentuk komunikasi data secara nirkabel berbasis frekwensi radio. Penggunaan utama dari modul Bluetooth ini adalah menggantikan komunikasi serial menggunakan kabel. Bluetooth terdiri dari dua jenis perangkat, yaitu Master (pengirim data) dan Slave (penerima). Modul HC-06 dari produsen koneksi secara default diset di kecepatan 9,600 bps (bisa dikustomisasi antara 1200 bps hingga 1,35 Mbps). Modul HC-06 hanya bisa berperan sebagai slave device, module selain modul bluetooth HC-06 ada modul Bluetooth HC05, modul ini dapat berperan juga sebagai bluetooth master device ataupun slave, secara default slave.

\section{4) WP3A - Wav Player Rev.A dilengkapi microSD}

WP3A adalah kit pemutar file musik wav (mono, $8 \mathrm{kHz}-44.1 \mathrm{kHz}$, 8bit) yang tersimpan didalam memori microSD. WP3A tidak dapat memutar file mp3 secara langsung. File mp3 perlu dikonversi menjadi file wav lalu disimpan ke dalam microSD. (Sumber:bttp:/ / wwm.bengkelelektro.com/)

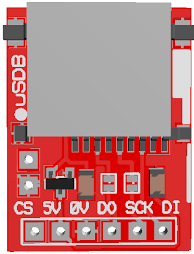

Gambar 4. Bentuk nyata WP3A

\section{5) Tunanetra}

Tunanetra adalah istilah umum yang digunakan untuk kondisi seseorang yang mengalami gangguan atau hambatan dalam indra penglihatannya. Berdasarkan tingkat gangguannya Tunanetra dibagi dua yaitu buta total (total blind) dan yang masih mempunyai sisa penglihatan (Low Visioan). Alat bantu untuk mobilitasnya bagi tuna 
netra dengan menggunakan tongkat khusus, yaitu berwarna putih dengan ada garis merah horisontal. Akibat hilang/berkurangnya fungsi indra penglihatannya maka tunanetra berusaha memaksimalkan fungsi indra-indra yang lainnya seperti, perabaan, penciuman, pendengaran, dan lain sebagainya sehingga tidak sedikit penyandang tunanetra yang memiliki kemampuan luar biasa misalnya di bidang musik atau ilmu pengetahuan.

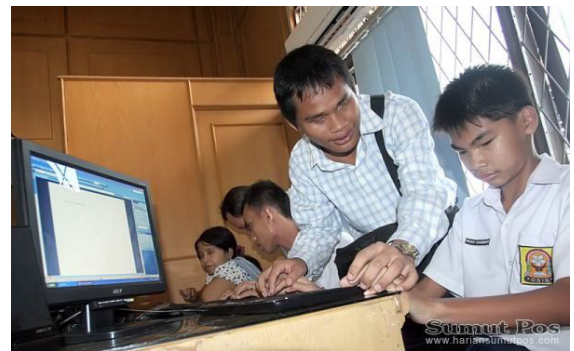

Gambar 5. Penyandang tunanetra dalam proses belajar mengajar

\section{Hasil}

Hasil yang dicapai oleh peneliti adalah sebuah aplikasi android yang dihubungkan dengan alat yang menyimpan file buku audio dengan format WAV dan modul bluetoth sebagai perantara atau penghubung. Aplikasi android yang digunakan bertujuan untuk mengirim sebuah perintah suara untuk memanggil buku yang tersimpan pada alat dengan penghubung modul bluetoth.
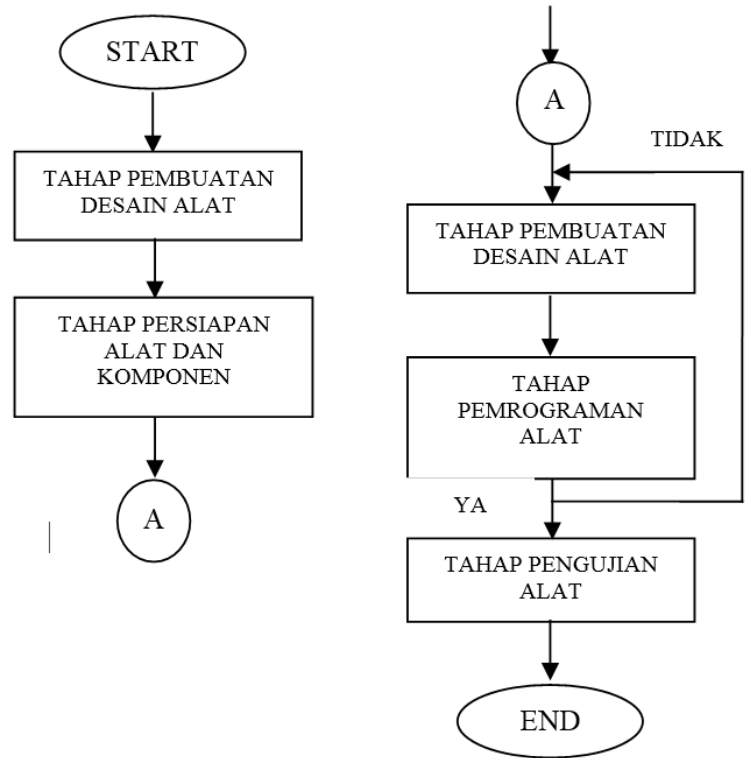

Gambar 6. Flowchart Penelitian

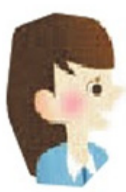

Membaca dan merekam novel
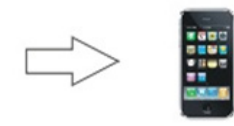

Proses perekaman

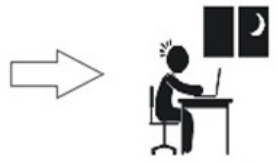

Pengeditan rekaman

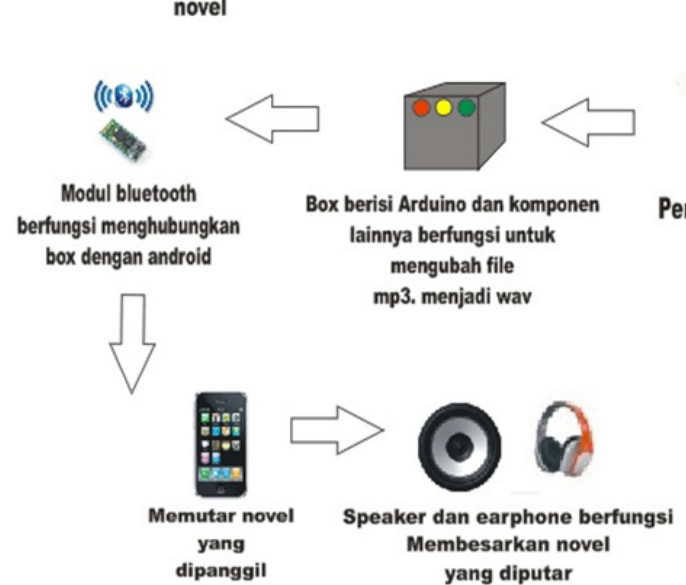

Gambar 7. Diagram alur rancangan proses untuk novel audio visual yang sudah diedit sampai dengan tahap output berupa speaker atau earphone.

\section{1) Tahap Pembuatan Desain Alat}

Tahap perancangan ini merupakan tahap dalam melakukan perancangan desain meliputi perancangan model alat yang sederhana dan sesuai, perancangan sistem kerja alat dan perancangan komponen yang akan digunakan. Cara kerja alat yang dirancang yaitu dengan menggunakan smarthphone android yang berfungsi sebagai perekam sekaligus tempat untuk memanggil novel audio yang sudah di edit, dan arduino berfungsi sebagai tempat untuk memproses atau mengolah hasil rekaman yang mau dipanggil serta outputnya berupa speaker atau earphone.

\section{2) Tahap Persiapan Alat dan Komponen}

Pada tahap ini peralatan yang digunakan yaitu solder, obeng, tang, multimeter. Sedangkan komponen yang digunakan arduino, smarthphone android, speaker/ earphone, modul bluetooth, mic, box, battrai li-po, papan PCB dan komponen lainnya. 


\section{3) Tahap Pembuatan Alat}

1) Pembuatan mekanik untuk novel audio visual sesuai dengan desain yang telah dibuat.

2) Pembuatan rangkaian elektronik.

3) Menginstal semua komponen menjadi satu dan pembuatan program alat.

\section{4) Tahap Pemrograman Alat}

Pemrograman yang digunakan menggunakan bahasa c yang diproses menggunakan arduino sebagai microprosesor yang mampu mensinkronisasikan semua komponen yang dipakai. Seperti memanggil buku audio yang disimpan di dalam micro sd.berikut pogram yang dibuat penulis.

\#include $<$ SoftwareSerial.h $>$

\#include $<$ Wp3a.h $>$

SoftwareSerial BT(2,3);//rx,tx

Wp3a wp3a(10,11);

String perintah;

void setup 0 \{

BT.begin(9600);

Serial.begin(9600);

\}

void loop0

//Serial.println("lup");

while (BT.available) )

delay(10);

char $\mathrm{c}=$ BT.read $($;

perintah $+=\mathrm{c}$;

Serial.println("belom siap");

\}

if(perintah.length $0>0)\{$

Serial.println(perintah);

// perintah dibawah ini dapat anda sesuaikan dengan perintah anda gan :v

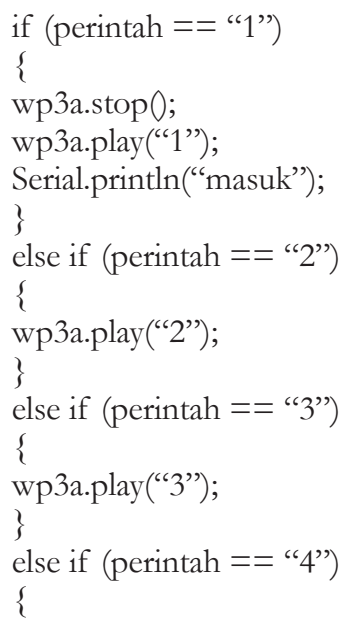

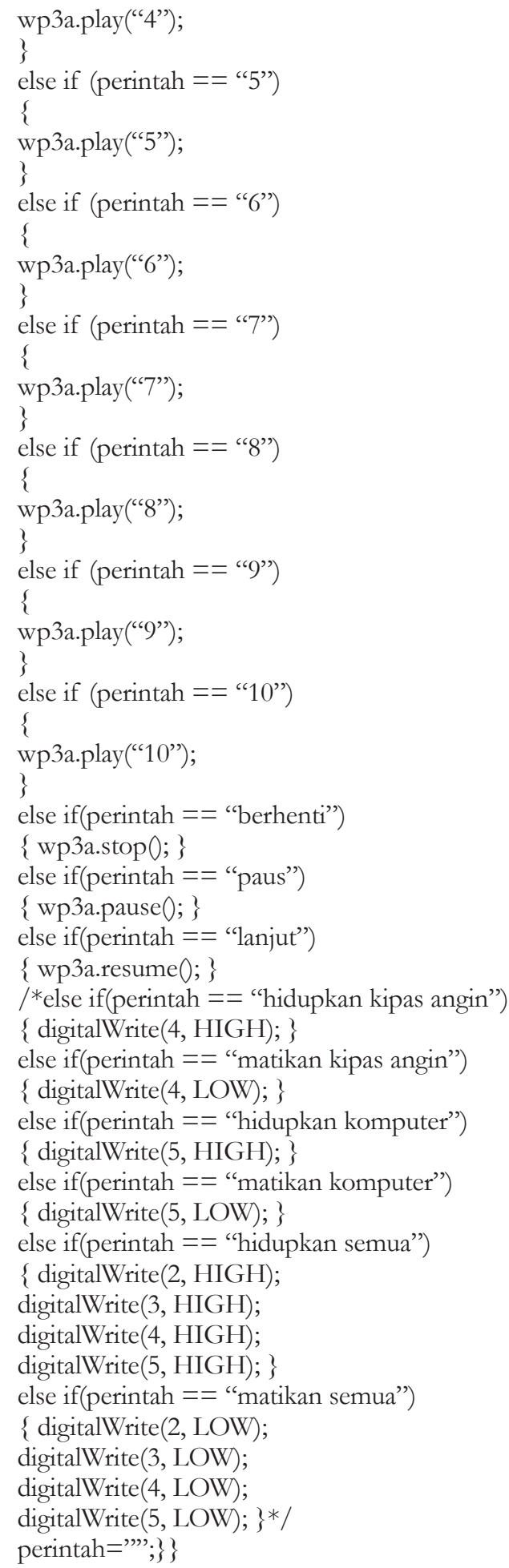

\section{5) Halaman Splash Screen}

Berikut ini merupakan halaman awal ketika masuk ke dalam aplikasi dan halaman awal splash screen akan tertutup kemudian masuk ke halaman menu utama. 


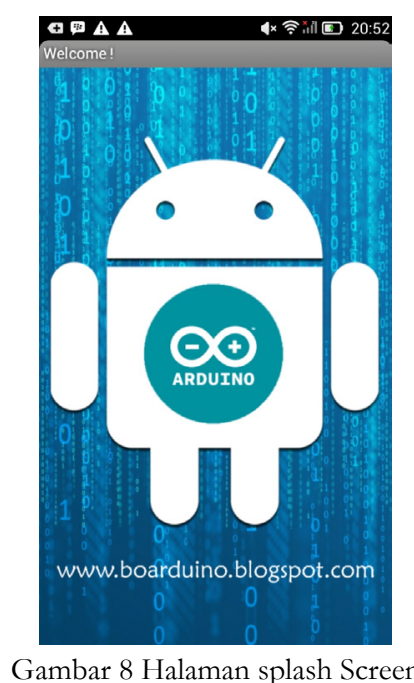

6) Halaman Menu Utama

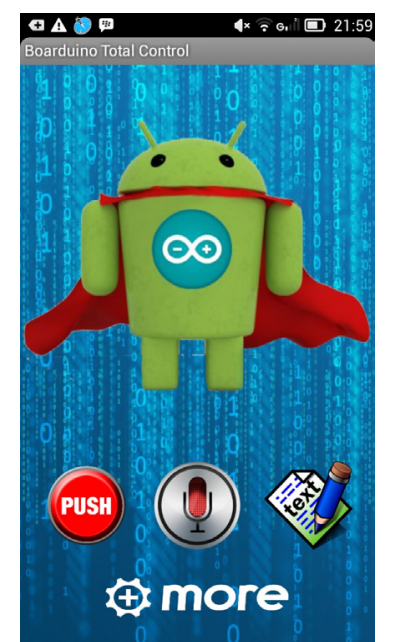

Gambar 9 Halaman Menu Utama

Halaman menu utama adalah halaman yang ditampilkan sesudah halman splash screen.

7) Halaman Untuk Pengaktifan bluetooth

Bu $\Psi$ (1)
00:00:46:65:72:01 EVERCOSS
A5C
98:D3:31:80:81:46 HC-05
24:E2:71:41:BE:29 MIUI
E0:2C:B2:42:AD:AA Lenovo
A7000-a
34:C8:03:44:DB:C4 Nokia 110
48:9D:24:1A:3E:A7
BLACKBERRY-B595
D4:93:98:26:C9:F8 Nokia_XL
Ku

Gambar 9. Halaman Pengaktifan Bluetooth
Halaman Pengaktifan bluetooth adalah halaman yang berfungsi menghubungkan android dengan alat penyimpan buku digital.

\section{8) Halaman Pemanggilan Buku audio}

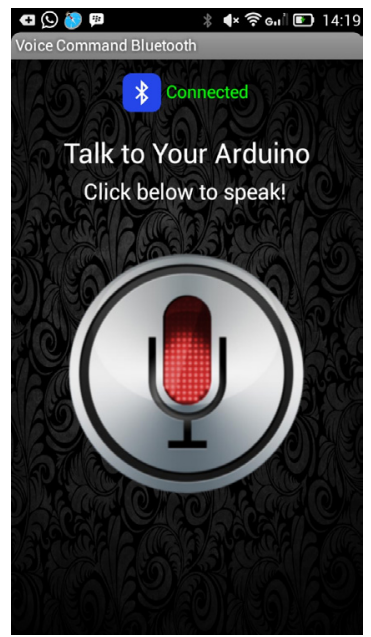

Gambar 10. Halaman Pemanggilan Buku audio

Halaman pemanggilan buku audio yaitu halaman yang menghubungkan bluetooth di smartphone dengan bluetooth di alat yang menyimpan file buku audio.

\section{9) Alat Penyimpan Buku Audio}

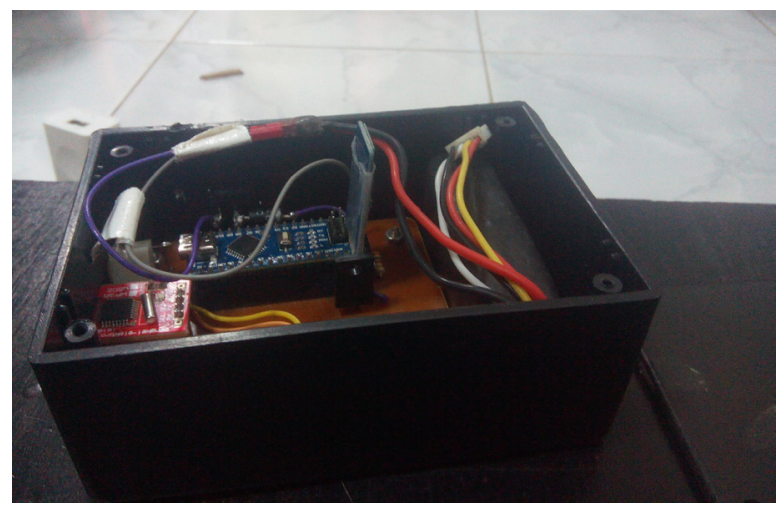

Gambar 11 Alat Penyimpan Buku Audio

Alat ini berfungsi untuk memanggil buku auido yang dipanggil melalui smarthphone android dan dikeluarkan oleh speaker atau headset.

\section{0) Tahap Pengujian Alat}

Pembuatan novel audio motivasi berbasis smarhphone android yang sudah dibuat akan diuji kepada penyandang tunanetra agar bermanfaat bagi penyandang tunanetra yang selama ini hanya bisa membaca novel brailler yang jumlahnya terbatas. Dan alat yang kami buat akan membantu sekali serta tidak menyusahkan para tunanetra yang selama ini hanya menggunakan huruf brailler saja untuk melakukan aktifitas membaca, sekarang kami memudahkan para tunanetra dengan android yan $g$ berfungsi memanggil per halaman dengan suara. Semoga alat yang kami buat bisa bermanfaat kedepannya bagi penyandang tunanetra. 


\section{1) Uji Validitas}

Pengujian validitas dan realibitas dilakukan, peneliti melakukan uji coba dengan menanyakan kepada para penyandang tunanetra. Penelitian ini dilakukan di yayasan pembinaan anak cacat (YPAC) Surakarta.gambar 11 adalah grafik hasil validitas data kuisioner pada anak-anak (YPAC) yang beralamatan di jalan slamet riyadi.

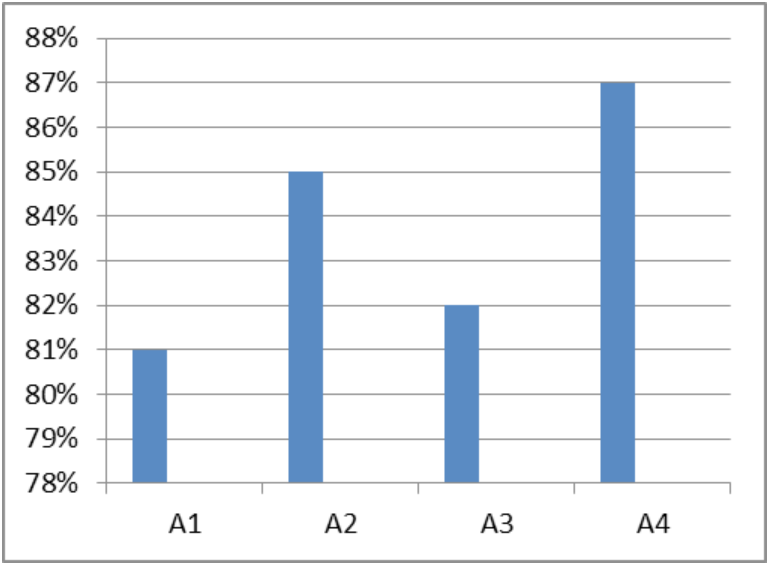

Gambar 12. Grafik Presentase Responden Anak (YPAC)

Keterangan Grafik :

A1: Aplikasi dan alat mudah digunakan

A2: Lebih memilih buku digital daripada buku brailer

A3: Audio yang dihasilkan oleh alat mudah di pahami

A4: Aplikasi dan Alat dapat meningkatkan keinginan untuk untuk review belajar

\section{Kesimpulan}

Kesimpulan dari penelitian ini adalah:

1) Perancangan dan pembuatan alat serta aplikasi android telah berhasil dibuat.
2) Berdasarkan hasil penelitian dan kuisioner anak (YPAC) telah dapat disimpulkan bahwa aplikasi dan alat yang dibuat telah berhasil mencapai tujuan yang diinginkan penulis karena telah mampu mewadahi anak-anak (YPAC) yang senang buku dalam bentuk audio secara menarik dan mudah dipahami.

\section{Daftar Pustaka}

[1] Departemen Kesehatan.data disabilitas. http:// www.depkes.go.id/Finfodatin_disabilitas.pdf.

[2] DWIYANTO, MUH RIZKI. 2014. Sistem Pengubah Teks Ke Suara Pada Aplikasi Penerjemahan Bahasa Indonesia Dan Inggris Secara Real Time Berbasis Smartphone Android. Jakarta: tugas akhir, UNIVERSITAS GUNADARMA.

[3] Elektro, Bengkel, 2014. WP3A - Wav Player Rev.A dilengkapi microSD. http://www.bengkelelektro. $\mathrm{com} /$ product.php? category $=1$ \&product_id $=248$,

[4] Malang, DiY tech, 2013, mengenal bluetooth modul he 05 . http://www.diytech-malang. com/2015/05/mengenal-bluetooth-modul-hc-05-1. html Pendidikan Anak Tunanetra.

[5] https://pendidikananaktunanetra.wordpress. $\mathrm{com} /$.../aspek-psikologis-anak.html

[6] Razzaaq Abdu,Tedy Junaedi.2013. Pengontrolan Lampu Dengan Menggunakan Suara Berbasis EASY VR.Makassar:Tugas Akhir,UNIVERSITAS HALU OLEO 